\title{
Youth in India: Situation and needs study
}

Population Council

Follow this and additional works at: https://knowledgecommons.popcouncil.org/departments_sbsr-pgy

Part of the Demography, Population, and Ecology Commons, Family, Life Course, and Society Commons, Gender and Sexuality Commons, and the International Public Health Commons How does access to this work benefit you? Let us know!

\section{Recommended Citation}

"Youth in India: Situation and needs study," update. New Delhi: Population Council, 2006. 

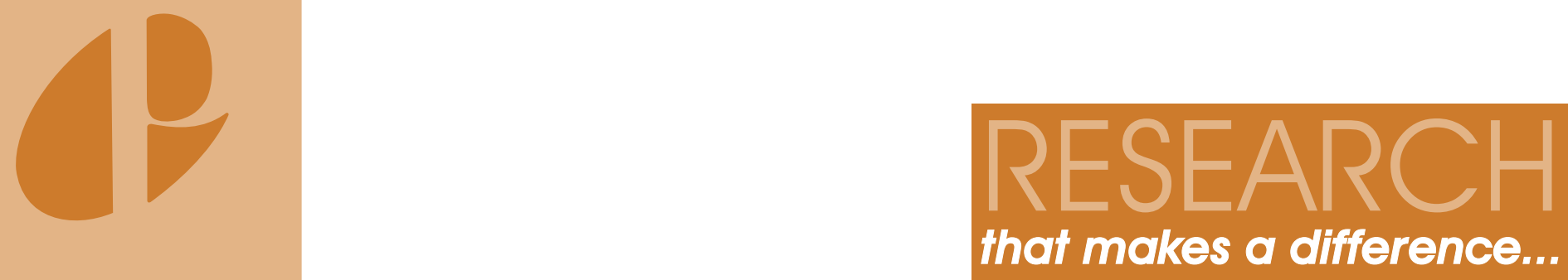

\author{
YOUTH IN INDIA: SITUATION AND NEEDS STUDY \\ Conducted by: International Institute for Population Sciences and Population Council
}

\section{Background}

Youth, the population aged 15-24, constitute some 222 million and represent 20 percent of the Indian population. This cohort is healthier, more urbanised and better educated than earlier generations; at the same time, they face significant risks related to sexual and reproductive health, and many lack the knowledge and power to make informed sexual and reproductive choices. These vulnerabilities remain poorly understood and served, and it is only over the last decade or so that researchers and policy makers have begun to shed their traditional ambivalence to these issues. Even so, information on intimate partnerships among youth, female and male, married and unmarried, is sparse and evidence is practically non-existent that identifies the factors that protect young people's ability to ensure safe sexual and reproductive health and their autonomy to make informed and wanted decisions. What is available derives from small and unrepresentative studies, making it difficult to generalise to youth in India.

A sub-national study of young people's situation and needs is currently ongoing that aims to fill these gaps. Six states have been selected for study, representing different geographical and socio-cultural parts of the country, namely, Andhra Pradesh, Bihar, Jharkhand, Maharashtra, Rajasthan and Tamil Nadu. Objectives are to (1) identify key transitions facing youth, including education and livelihood opportunities and experiences; (2) provide evidence at state level on the magnitude and patterns of sexual and reproductive practices in and outside of marriage, and related knowledge, decision-making and attitudes among youth; and (3) identify key factors underlying their sexual and reproductive health, knowledge, attitudes and life choices. The study is being implemented by the International Institute for Population Sciences, Mumbai, in collaboration with the Population Council, New Delhi and with financial support from the Packard and MacArthur Foundations.

The study design involves pre- and postsurvey qualitative phases and a survey of some 10,000-12,000 married and unmarried females and males residing in rural and urban parts of each of the six selected states. It focuses on unmarried youth and married females aged 15-24 and, in view of the paucity of married males in these ages, married males aged 15-29. The pre-survey qualitative phase aimed to collect information on youth norms and experiences through focus group discussions (FGDs) with young people; youth experiences and needs from key informant interviews with health care providers, teachers and others involved with youth, and parental perspectives from indepth interviews (IDIs) with parents of young unmarried and married women and men. Insights from FGDs informed the content and language of the survey 
instruments, which have been designed to cover a range of issues: schooling and employment, friendship and sex, marriage and childbearing, voting experience, community violence, available programmes for youth and key youth needs. In a final phase of study, conducted in parallel with the survey, upto 72 respondents in each state reporting sensitive and relatively rare experiences, are interviewed in-depth in order to obtain a better understanding of the context and interpretations of such experiences.

The complexities of conducting such a study, especially to devise rigorous, indepth and, at the same time, sensitive and culturally appropriate research designs to elicit these data, given the sensitive nature of topics relating to youth sexuality, and the lack of sound precedents cannot be undermined. We describe below major accomplishments of the study attained thus far.

Pre-survey qualitative phase: This phase, comprised FGDs with youth, key informant interviews with youth leaders, community leaders, teachers, health care providers and others working with youth, and IDIs with parents of youth. This phase was completed in all six states during 2005 and covered settings representative of the entire state. In four states, this involved a total of nine sites (six rural and three urban), representing different socio-geographic regions; in the remaining two states, work was undertaken in a total of eight sites (five rural and three urban). A total of 104 FGDs, 231 key informant interviews and 415 parent IDIs were completed over the six states under study. FGD data were used to inform the survey instrument. Analysis of key informant and parent IDI data is currently ongoing.

Survey phase: In each state, a total of 300 (150 villages and 150 urban census enumeration blocks) primary sampling units (PSUs) were selected for survey. The strategy is to interview young women in one half and young men in the other half of selected PSUs. Instruments include a household, four individual and one rural community questionnaire.

In view of the complexities of the study, it was decided to conduct the surveys in two phases: Maharashtra, Jharkhand and Tamil Nadu in the first phase and Bihar, Rajasthan and Andhra Pradesh in the second. Fieldwork in the three Phase-1 states has either been completed already or will be completed by the end of 2006. Prior to initiation of fieldwork in each of these states, a house-listing operation was undertaken and an extensive training programme lasting three weeks was undertaken for field interviewers in each state that included lectures and interactive sessions on a range of issues.

Post-survey qualitative phase: The postsurvey qualitative phase comprising upto 72 IDIs with selected survey respondents in each state, has been implemented together with the survey. Thus far, 42, 61 and 35 IDIs have been completed in Maharashtra, Jharkhand and Tamil Nadu, respectively.

Prior to launching the study we feared community hostility and youth refusal to consent to be interviewed. While our teams have occasionally experienced hostility, on balance, the reception received by field teams in all the states thus far has been remarkably positive and in some areas both male and female youth were really eager to be interviewed and responded readily to questions about their sexual experiences. Preliminary findings suggest that significant minorities of young women and men report pre-marital sexual experience.

What's next: Analysis has recently been initiated by International Institute for Population Sciences and Population Council researchers on data from rural Maharashtra; we envisage that findings for all Phase- 1 states will be available by early 2007 . Fieldwork for Phase 2 states will be initiated from November 2006.
International Institute for Population Sciences

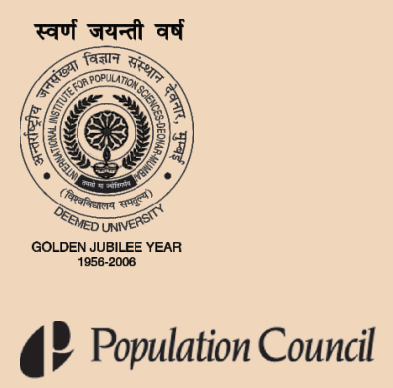

For further information please contact:

International Institute for Population Sciences

Govandi Station Road

Deonar, Mumbai - 400 088, INDIA

Tel: 91-22-2556 3254-56

Fax: 91-22-2556 3257

Email: iipsyouth@rediffmail.com

www.iipsindia.org

Population Council

Zone 5A, Ground Floor

India Habitat Centre, Lodi Road

New Delhi - 110 003, INDIA

Tel: 91-11-2461 2901/02

Fax: 91-11-2464 2903

Email: info-india@popcouncil.org

www.popcouncil.org

Study Team:

P.N. Mari Bhat, Faujdar Ram,

Usha Ram, Sanjay K. Mohanty,

Abhishek Singh (International

Institute for Population Sciences);

Shireen Jejeebhoy, K.G. Santhya,

Rajib Acharya (Population Council)

\section{Donors}

The David and Lucile

Packard Foundation,

The John D. and Catheine T.

MacArthur Foundation 